\title{
Magnetizing Roasting of low grade Iron Minerals from Akoko Area, southwestern Nigeria using Fluidized Bed Reactor
}

\section{Olugbenga A. EhinOLA ${ }^{1,2}$ AND QINShan ZhU ${ }^{1}$}

${ }^{1}$ Institute of Process Engineering, CAS, Multiphase Reaction Laboratry, Beijing, China

${ }^{2}$ Energy and Environmental Research Group, Department of Geology, University of Ibadan, Nigeria

Magnetizing roasting using fluidized bed reactor is adopted on samples from Akunu (AK), Ikare (IK) and Oke Oka (OOK) in Akoko Area of southwestern Nigeria in order to determine their iron $(\mathrm{Fe})$ concentration by reduction methods.

The samples were roasted for $3,5,7$ and 10 minutes at temperature of $550{ }^{\circ} \mathrm{C}$ using $0.4 \mathrm{~N}_{2}$ and $0.2 \mathrm{H}_{2}$ gas at 1.0 $\mathrm{L} / \mathrm{min}$. The roasted samples were then diluted and separated into concentrate and tail (T) using magnetic separator machine. The concentrate was directly reduced to $\mathrm{Fe}$ at 750 ${ }^{\circ} \mathrm{C}$ temperature using $0.5 \mathrm{~N}_{2}$ and $0.5 \mathrm{H}_{2}$ gas at $1.0 \mathrm{~L} / \mathrm{min}$. Xray fluorescence (XRF), X-ray diffractometry (XRD) and Scan electron microscope-energy dispersive X-ray spectrometry (SEM-EDS) were used to determine the composition, crystalline nature and structure of the concentrate.

The concentrate and tail from AK roasted samples ranged from 95.1-99.03 and 0.97-4.90\% while that of OOK ranged from 59.41-67.65 and 32.35-40.59\% respectively. The IK concentrate and Tail is $13.54-20.32$ and $79.68-87.46 \%$. The XRF, XRD and SEM results show that the dominant minerals in $\mathrm{AK}$ are hematite $(\mathrm{Fe})$, silica $(\mathrm{Si})$, manganese $(\mathrm{Mn})$ and alumina (Al). The $\mathrm{Mn}, \mathrm{Si}$ and $\mathrm{Al}$ are the main component of the $\mathrm{T}$. The direct reduction of the AK and OOK concentrates to Fe show an increase from 62.7 and $37.5 \%$ to 91.4 and 66.7 $\% \mathrm{Fe}$ respectively.

AK could be fed into a blast furnace directly after initial roasting and could also be reduced directly to Fe while OOK and IK may not be economical as their $\mathrm{T}$ are high and also have low $\mathrm{Fe}$ concentrate. A pilot plant may be required for $\mathrm{AK}$ and large scale production of $\mathrm{Fe}$ can be achieved through this method at low cost. 